\title{
Story map media: Inovasi pembelajaran Geografi dalam materi mitigasi bencana
}

\author{
Impron Saputra, Yusuf Suharto*, Rudi Hartono \\ Universitas Negeri Malang, Jl. Semarang No. 5 Malang, Jawa Timur, Indonesia \\ *Penulis korespondensi, Surel: yusuf.suharto.fis@um.ac.id
}

Paper received: 03-01-2021; revised: 15-01-2021; accepted: 30-01-2021

\begin{abstract}
The development of learning media is based on the problems that occur today, namely the lack of utilization of learning media in the learning process. The use of learning media at SMAN 1 is one of them. Most students use learning methods that are still monotonous, because there are still many who use monotonous and teacher-centered learning methods at school. The purpose of developing research is to produce innovative learning media products. The media intended to be an easy-to-use media in this case is the story map media. As per the development of the 21 st century and the current 4.0 industrial revolution, which requires digital based media. The use of digital-based media in addition to being easy to use, also teaches students the usefulness of technology. The development model in this study follows the development model adapted from the ADDIE instructional design model which includes the analysis (design), design (development), development (implement) and evaluation stages. The results of the media feasibility trials in the field have a percentage of (75.9\%) which states that it is feasible, while the percentage $(24.1 \%)$ states that the media is very feasible. The results of the tests of understanding tests were obtained (82.7\%) students were able to answer questions well. Based on the results of feasibility trials and understanding tests in the field stated that the media is feasible to use and effectively used to help the learning process at school.
\end{abstract}

Keywords: learning media; story map; disaster mitigation; adaptatio natural disaster

\begin{abstract}
Abstrak
Pengembangan media pembelajaran ini didasarkan pada permasalahan yang terjadi saat ini yaitu kurangnya pemanfatan media pembelajaran dalam proses pembelajaran. Pemanfaatan media pembelajaran di SMAN 1 Tumpang salah satunya. Siswa kebanyakan menggunakan cara belajar yang masih monoton, karena di sekolah masih banyak yang menerapkan metode pembelajaran yang monoton dan terpusat pada guru. Tujuan dilakukannya penelitian pengembangan yaitu menghasilkan produk media pembelajaran yang inovatif. Media yang dimaksudkan merupakan media yang mudah digunakan dalam hal ini adalah media story map. Sesuai perkembangan abad 21 dan revolusi industri 4.0 saat ini, yang membutuhkan media berbasis digital. Kegunaan media yang berbasis digital selain mudah digunakan, juga mengajarkan kepada siswa kegunaan dari teknologi. Model pengembangan pada penelitian ini mengikuti model pengembangan yang diadaptasi dari model desain instruksional ADDIE yang meliputi tahap analisis (analysis), desain (design), pengembangan (development), implementasi (implement) dan evaluasi (evalutation). Hasil uji coba kelayakan media dilapangan didapatkan persentase sebesar $(75,9 \%)$ yang menyatakan layak, sementara persentase $(24,1 \%)$ meyatakan media sangat layak. Hasil dari uji coba tes pemahaman didapatkan hasil $(82,7 \%)$ siswa mampu menjawab pertanyaan dengan baik. Berdasarkan hasil uji coba kelayakan dan tes pemahaman dilapangan menyatakan bahwa media layak digunakan serta efektif digunakan untuk membantu proses pembelajaran disekolah.
\end{abstract}

Kata kunci: media pembelajaran; story map; mitigasi bencana; adapatasi bencana alam

\section{Pendahuluan}

Perkembangan ilmu pengetahuan semakin pesat dengan adanya teknologi. Peranan teknologi dalam memajukan dan mendorong kemajuan pendidikan sangat terlihat. Adanya teknologi ilmu pengetahuan mudah untuk diakses. Ilmu pengetahuan dapat dengan mudah 
dibagikan, bahkan dapat diunduh secara gratis. Hal tersebut tidak terlepas dari pengaruh teknologi, dalam hal ini adalah jaringan internet. Internet dewasa ini telah memberikan kemudahan dalam menyalurkan berbagai informasi. Perkembangan kemajuan internet dirasa memberikan dampak positif bagi kemajuan dunia pendidikan. secara umum internet berpengaruh terhadap terbentuknya media-media pembelajaran yang ada di sekolah.

Peranan media di sekolah dewasa ini telah memberikan suatu gambaran bahwa media sangat berpengaruh terhadap proses belajaran mengajar di sekolah. Media pembelajaran memegang peranan yang penting dalam proses pembelajaran (Ali, 2009). Adanya kemajuan teknologi saat ini menuntut sekolah untuk memberikan suatu layanan sarana dan prasarana terkait kemudahan dalam belajar. Teknologi yang sering dimanfaatkan oleh guru saat ini adalah handphone dan laptop. Kedua alat ini merupakan suatu alat penyalur informasi apabila digunakan secara bijak dan benar.

Penggunaan media untuk dijadikan sebuah saran penunjang pembelajaran masih sangat kurangg. Banyak guru geografi masih menggunakan media yang terlalu monoton, bahkan hanya buku untuk mengajar. Media yang jarang dimanfaatkan berpengaruh terhadap cara belajar siswa, yang mana siswa lebih suka penggunaan media yang lebih inovatif dan tidak terpaku pada buku. Geografi memberikan pemahaman dengan mengembangkan kemampuan intelektual siswa. Siswa dapat meningkatkan rasa ingin tahu dan daya observasi terhadap materi pembelajaran yang tinggi.

Geografi merupakan mata pelajaran yang menganalisis aspek fisik dan hubungannya dengan manusia. Mata pelajaran geografi memerlukan media yang bisa mencirikan atau membedakan dengan mata pelajaran lainnya yaitu penggunaan peta. Penggunaan peta dirasa masih kurang sampai saat ini. Peta merupakan sebuah media yang dapat dimanfaatkan dalam pembelajaran. Kedepannya guru geografi perlu menambahkan wawasan geospasial berupa pemanfaatan peta dalam pembelajaran di sekolah, khususnya terkait mata pelajaran geografi.

Sejalan dengan uraian di atas, maka diperlukan sebuah pengembangan media pembelajaran story map pada materi mitigasi dan adaptasi bencana alam. Oleh karena itu peneliti melakukan penelitian tindak lanjut "Pengembangan Media Pembelajaran Geografi SMA Berbasis Story Map pada Materi Mitigasi dan Adaptasi Bencana Alam". Harapannya agar siswa dapat terbantu dalam proses pembelajaran terkait materi mitigasi dan adaptasi bencana alam.

\section{Metode}

Penelitian ini bertujuan untuk mengembangkan produk media pembelajaran geografi SMA berbasis story map pada materi mitigasi dan adaptasi bencana alam. Model pengembangan pada penelitian ini mengikuti model pengembangan yang diadaptasi dari model desain instruksional ADDIE yang meliputi tahap analisis (analysis), desain (design), pengembangan (development), implementasi (implement) dan evaluasi (evalutation). Desain pengembangan $A D D I E$ adalah salah satu proses yang bersifat interaktif dengan tahapantahapan dasar pengembangan yang efektif, dinamis, dan efisien. Model pengembangan ADDIE dapat digunakan untuk berbagai macam bentuk pengembangan. Bentuk pengembangan produk seperti strategi pembelajaran, media dan bahan ajar. Model pengembangan menggunakan $A D D I E$ dapat dijadikan pedoman dalam membangun perangkat yang bersifat efektif, dinamis, dan efisien. Berikut ini merupakan rumus yang digunakan dalam menentukan kelayakan media dan keefektifan media pembelajaran. 
Rumus pertama untuk per item:

$$
\mathrm{N}=\frac{x}{x i} x 100
$$

Rumus kedua untuk keseluruhan data:

$$
\mathrm{N}=\sum \frac{x}{x i} x 100
$$

Tabel 1. Kriteria Kelayakan Media

\begin{tabular}{llll}
\hline Nilai & Total Skor & Kualifikasi & Keputusan dan Tindak Lanjut \\
\hline A & $80,1-100,0$ & Layak & Bisa digunakan tanpa revisi \\
B & $60,1-80,0$ & Cukup Layak & Bisa digunakan tapi perlu revisi kecil \\
C & $\leq 60,0$ & Tidak Layak & Bisa digunakan tapi perlu revisi besar \\
\hline
\end{tabular}

Sumber: Adaptasi dari tabel Akbar, (2013:82)

$$
P=\frac{\sum x}{\sum x i} \times 100 \%
$$

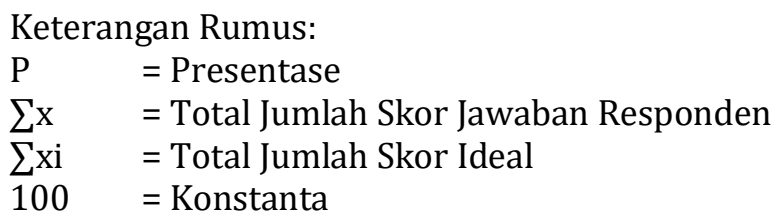

Tabel 2. Kriteria Keefektifan Media

\begin{tabular}{llll}
\hline Nilai & Total Skor & Keefektifan Media & Keputusan dan Tindak Lanjut \\
\hline A & $91-100$ & Sangat Efektif & Sangat disarankan untuk dipakai \\
B & $75-90$ & Efektif & Disarankan untuk dipakai \\
C & $60-74$ & Cukup Efektif & Boleh disarankan untuk dipakai \\
D & $43-59$ & Tidak Efektif & Tidak disarankan untuk dipakai \\
E & $<43$ & Sangat Tidak Efektif & Sangat tidak disarankan untuk dipakai \\
\hline
\end{tabular}

Sumber: Adaptasi dari pedoman klasifikasi nilai di SMAN 1Tumpang.

\section{Hasil dan Pembahasan}

Pengembangan dalam penelitian ini memiliki tujuan yaitu hasil berupa media pembelajaran. Adapun media yang dikembangkan merupakan media baru dalam pembelajaran di sekolah. Proses pembuatan media ini menggunakan aplikasi arcgis online yang nanti menghasilkan media pembelajaran berbasis story map pada materi mitigasi dan adaptasi bencana alam. Pengembangan media pembelajaran story map menggunakan data yang didapatkan dari total skor dan hasil tes. Total skor didapatkan melalui angket uji coba dan nilai tes didapatkan dari tes subjek uji coba. Penggunaan data total skor dan hasil tes dimaksudkan untuk mengetahui tingkat kelayakan media dan keefetivitasan media.

Tabel 3. Kelayakan Media dari Aspek Penggunaan

\begin{tabular}{lllll}
\hline Klasifikasi & Total Skor & Kualifikasi & Frekuensi & Presentase \\
\hline A & $80,1-100,0$ & Layak & 22 & 85,5 \\
B & $60,1-80,0$ & Cukup Layak & 7 & 14,5 \\
C & $\leq 60,0$ & Kurang Layak & 0 & 0 \\
\hline Jumlah & & & 29 & 100 \\
\hline
\end{tabular}


Berdasarkan hasil uji coba kelayakan media story map di sekolah. Didapatkan hasil 85,5\% siswa menyatakan media story map layak digunakan sebagai media pembelajaran di sekolah. Sementara $14,5 \%$ siswa lainnya menyatakan media story map cukup layak digunakan sebagai media di sekolah.

Tabel 4. Data Distribusi Frekuensi Hasil Tes Subjek Uji Coba

\begin{tabular}{llllll}
\hline Klasifikasi & Total Skor & Kualifikasi & Frekuensi & Presentase & Keterangan \\
\hline A & $91-100$ & Sangat Baik & 10 & 34,57 & Sangat efektif \\
B & $75-90$ & Baik & 12 & 41,46 & Efektif \\
C & $60-74$ & Cukup & 7 & 24 & Cukup efektif \\
D & $43-59$ & Kurang & 0 & 0 & Tidak efektif \\
E & $<43$ & Sangat Kurang & 0 & 0 & Sangat tidak efektif \\
\hline Jumlah & & & 29 & 100 & \\
\hline
\end{tabular}

Berdasarkan hasil uji coba keefektifan media story map di sekolah. Didapatkan hasil $34,57 \%$ siswa menyatakan media story map sangat efektif digunakan sebagai media pembelajaran di sekolah. Sementara hasil presentase kedua didapatkan hasil 41,46\% siswa menyatakan media story map efektif digunakan sebagai media di sekolah. Hasil terakhir menyatakan media story map cukup efektif digunakan di sekolah dengan nilai presentase sebesar $24 \%$.

Berdasarkan data hasil uji coba di sekolah, didapatkan hasil kelayakan media dan keefektifan media pembelajaran. Analisis data dilakukan setelah melakukan uji coba produk pada subjek uji coba. Perolehan data melalui uji coba dianalisis untuk mengetahui tingkat kelayakan dan keefektifan media pembelajaran. Titik berat untuk menentukan layak atau tidaknya media melalui hasil total skor angket uji coba. Berbeda dengan cara menentukan keefektifan media yang didapatkan melalui hasil nilai tes siswa. adapun analisis data dari penelitian ini sebagai berikut.

\subsection{Analisis Data Total Skor Angket Uji Coba}

Analisis data total skor angket merupakan langkah lanjutan setelah dilakaknnya penelitian. Berdasarkan data yang diperoleh dari hasil uji coba lapangan didapatkan bahwa sebagian besar siswa berpendapat bahwa media ini layak digunakan dan sebagaian lagi siswa berpendapat bahwa media sangat layak digunakan. Hasil uji coba dilapangan didapatkan presentase sebesar $(85,5 \%)$ yang menyatakan layak, sementara yang presentase $(14,5 \%)$ meyatakan media cukup layak. Berdasarkan hasil tersebut dapat dikatakan bahwa media pembelajaran geografi SMA berbasis stroy map pada materi mitigasi dan adaptasi bencana alam dapat digunakan sebagai media pembelajaran.

\subsection{Analisis Data Hasil Tes Pemahaman}

Penelitian media ini juga mencari data hasil nilai tes pemahaman untuk digunakan sebagai tolak ukur keefektifan media. Berdasarkan hasil dari uji coba tes penilaian didapatkan hasil $(76,03 \%)$ siswa mampu menjawab pertanyaan dengan baik. Adapun nilai yang didapatkan oleh sebagian besar siswa terletak pada kualifikasi sangat baik, baik dan cukup baik. Presentase siswa yang mendapatkan nilai sangat baik dan baik berada dikisaran (34, 
$57 \%)$ dan $(41,46 \%)$. Sementara siswa yang mendapatkan kualifikasi nilai yang cukup baik sebesar (24\%).

Berdasarkan pemaparan data hasil uji coba di atas, dapat diakatakan bahwa media pembelajaran story map memberikan dampak yang positif terkait proses pembelajaran. Pemanfaatan media pembelajaran ini mendapatkan hasil yang baik terkait membantu siswa memahami materi dengan lebih baik dengan hasil presentase sebesar $(76,03 \%)$. Setelah melalui tahapan di atas, maka dapat diambil suatu kesimpulan bawasannya media pembelajaran geografi SMA berbasis story map pada materi mitigasi dan adaptasi bencana alam efektif digunakan sebagai media pembelajaran di sekolah.

\section{Simpulan}

Berdasarkan hasil uji coba media pembelajaran didapatkan hasil media pembelajaran story map layak dan efektif digunakan dalam proses pembelajaran di sekolah. Pemanfaatan media digunakan untuk mendorong berlangsungnya proses pembelajaran agar lebih efektif, efisien, dan menghemat waktu. Adapun agar media dapat digunakan secara optimal, maka perlunya sebuah saran pemanfaatan, desiminasi, dan pengembangan produk lebih lanjut.

Adapun saran pemanfaatan merupakan tanggapan yang diberikan oleh pengguna untuk media yang telah dikembangkan. Tanggapan pengguna terhadap media ditujukan untuk membangun dari segi kekurangan dari media ini, sehingga diharapkan kedepannya pemanfaatan media ini dapat berjalan lancar. Segi pemanfaatan media ini sebelum digunakan sebaiknya mempersiapkan segala kebutuhan yang diperlukan. Kebutuhan media ini seperti halnya PC/Laptop yang mempunyai spesifikasi yang mumpuni, LCD proyektor, dan sound Sytem agar pemanfaatan media dapat berjalan dengan baik serta lancar. Pemanfaatan media ini menggunakan aplikasi arcgis online. Media ini menggunakan jaringan internet. Jaringan internet diperlukan untuk mengakses alamat website, karena media berbentuk media online.

Desiminasi merupakan suatu langkah penyebar luasan media pembelajaran. Hal tersebut dilakukan untuk menyebar luaskan media pembelajaran ini agar dapat bermanfaat bagi dunia pendidikan. Media ini mudah digunakan dan tidak memerlukan peralatan khusus layaknya media lainnya. Produk media ini dapat disebarluaskan melalui media onine. Media online bisa berupa blogger, wordpress, facebook, twitter dan media online lainnya. Caranya dengan menyisipkan alamat media didalam media online tersebut. Sejalan dengan kemajuan zaman yang sudah modern, proses penyebarluasan media ini tidak mengalami kendala. Guru dan siswa dapat memanfaatkan media ini untuk membantu proses pembelajaran. Pada saat uji penyebarluasannya melalui facebook. Hal tersebut dilakukan, karena sebagian besar siswa masih mempunyai akun facebook.

Pengembangan produk lebih lanjut dimaksudkan untuk mengembangkan suatu produk media yang baru dan lebih baik dari media sebelumnya. Hal itu dilakukan untuk membuat media yang mempunyai inovasi lebih baik dari pengembangan media sebelumnya. Media sebelumnya tentunya memiliki kelemahan, maka dari itu pengembangan media ini kedepannya diharapkan mampu menutupi kekurangan produk media sebelumnya. Produk pengembangan lebih lanjut diharapkan menggunakan aplikasi arcgis online dengan materi yang berbeda, sehingga media tidak hanya terpaku pada satu materi. 
Jurnal Integrasi dan Harmoni Inovatif IImu-Ilmu Sosial (JIHI3S), 1(1), 2021, 94-99

\section{Daftar Rujukan}

Ali, M. (2009). Pengembangan media pembelajaran interaktif mata kuliah medan elektromagnetik. Jurnal edukasi elektro, $5(1)$.

Akbar, S. (2013). Instrumen Perangkat Pembelajaran. Bandung: Remaj Rosdakarya

Asyhar, R. (2012). Kreatif Mengembangkan Media Pembelajaran. Jakarta: Referensi.) ^(Eds.): 'Book Kreatif Mengembangkan Media Pembelajaran. Jakarta: Referensi' (GP Press Group, 2012, edn.).

Ibrahim, dkk. (2004). Media Pembelajaran. Malang. FIP Universitas Negeri Malang.

Muslimin dan Ramli. (2016). Media Pembelajaran Berbasis Animasi Power Point Untuk Meningkatkan Hasil Belajar Geografi Kelas X SMA Negeri 10 Kendari. Jurnal Pendidikan Geografi. 1 (1).

Gillen, J., Skryzhevska, L., Henry, M. C., \& Green, J. (2010). Map interpretation instruction in introductory textbooks: A preliminary investigation. Journal of Geography, 109(5), 181-189.

Prasetya, S. P. (2014). Media Pembelajaran Geografi. Yogyakarta: Ombak.

Purwanto, P., \& Kistiyanto, M. S. (2017). Dinamika Spatio-Temporal Dampak Erupsi Gunung Kelud di Kabupaten Kediri. Jurnal Pendidikan Geografi: Kajian, Teori, dan Praktek dalam Bidang Pendidikan dan Ilmu Geografi, 22(1), 60-72.

Setyosari,P. dan Sihkabuden. (2005). Media Pembelajaran. Malang: Elang Emas

Sinaga, N. S., \& SKM, M. K. (2015). Peran petugas kesehatan dalam manajamen penanganan bencana alam. Jurnal ilmiah “INTEGRITAS” Vol, 1(1).

Strachan, C., \& Mitchell, J. (2014). Teachers' perceptions of Esri Story Maps as effective teaching tools. Review of International Geographical Education Online, 4(3), 195-220. 